\title{
Oh, as for the Health Insurance...it's good, but....: rural elders in Agate, Ghana, discuss the National Healthcare Insurance Scheme
}

\author{
Eileen Smith-Cavros, ${ }^{1}$ Joyce Avotri-Wuaku, ${ }^{1}$ Albert Wuaku, ${ }^{2}$ Amal Bhullar ${ }^{3}$ \\ ${ }^{1}$ Department of Conflict Resolution Studies, Nova Southeastern University, Fort Lauderdale, FL; \\ ${ }^{2}$ Religious Studies Department, School of International and Public Affairs, Florida International University, Miami, FL; \\ ${ }^{3}$ Department of Biological Sciences, Nova Southeastern University, Fort Lauderdale, FL, USA
}

\begin{abstract}
This paper investigates the Ghanaian National Healthcare Insurance Scheme (NHIS) through interviews with 28 elders over 50 years old with pre-existing illnesses in Agate, a rural village in Ghana. Our goals were to obtain snapshot views of the lives, in relation to health, wellness, and NHIS, of participants. Elders possessed reasonable information about NHIS. For most enrollees, NHIS provided peace of mind against financially-related health challenges, however, inability to afford non-covered medicines sometimes interfered with treatment. Most interviewees, insured or not, reported continuing chronic health problems. Based on qualitative data, we describe possibilities to improve elder experiences including: transportation to medical care, increased drug coverage, and faith-based health partnerships.
\end{abstract}

Correspondence: Eileen Smith-Cavros, Department of Conflict Resolution Studies, Nova Southeastern University, 33314 Fort Lauderdale, FL, USA

Tel: +1.954.2628172.

E-mail: eilesmit@nova.edu

Key words: Elders; Health; Policy; Africa; Qualitative study

Contributions: ES-C arranged transcription of interviews, coding, data analysis, literature research, wrote portions of article, edited article, project photographer; JAW conducted interviews, data analysis, literature research, wrote portions of article, edited article; AW conducted interviews, initial data analysis, literature research, wrote portions of article, edited article; AB coding, data analysis, literature research, wrote portions of article, edited article.

Conflict of interest: the authors declare no potential conflict of interest.

Funding: financial support for this project was provided through Nova Southeastern University President's Faculty Research and Development Grant project \#335869.

Acknowledgements: the authors would like to thank the villagers of Agate, Ghana for generously sharing their stories with us and we are also grateful to the Chief and community council of elders for their assistance. We thank our friend and driver Chuku for his help and knowledge in the field and on the road. Finally, we posthumously extend our gratitude to Dr. Samuel Wuaku for his hospitality during our fieldwork and his many years serving the medical needs of the people of Ghana.

Received for publication: 21 September 2016.

Revision received: 16 November 2016.

Accepted for publication: 30 November 2016.

This work is licensed under a Creative Commons Attribution NonCommercial 4.0 License (CC BY-NC 4.0).

CCopyright E. Smith-Cavros et al., 2017

Licensee PAGEPress, Italy

Qualitative Research in Medicine \& Healthcare 2017; 1:23-28

doi:10.4081/qrmh.2017.6300

\section{Introduction}

This paper examines attitudes about the National Healthcare Scheme (NHIS) in Ghana, West Africa, through qualitative research. Specifically we offer accounts by elders (which we define as members of the population 50 years and older) with pre-existing health challenges in the village of Agate. This group is important since the proportion of the population older than 60 is estimated to reach $12 \%$ in $2050 .^{1(\mathrm{p} .1)}$

This research is shaped by our position (as a research team) that healthcare is a human right and that a properly functioning and funded program providing universal coverage to all citizens (with hands-on citizen participation) can promote improved physical and social well-being.

Ghana, population 25 million, ${ }^{2(p .1)}$ is categorized as lower-middle income by the United Nations. ${ }^{3}$ Poverty predominates in rural areas and a quarter of Ghanaians are poor using measures of consumption poverty, lack of access to assets and services and human development. ${ }^{3(p .3)}$

After declaring independence from British rule in 1957, healthcare was available without point of service fee. ${ }^{4(\mathrm{p} .128)}$ This changed to a cash and carry system in the 1980s, ${ }^{5}$ creating access obstacles. ${ }^{4}$ President Kufuor (elected 2001 and 2005), ${ }^{6}$ attempted to provide national healthcare for all and The National Health Insurance Law passed in 2003.

According to the district schemes there is a minimum premium and the plan covers $95 \%$ of prevalent diseases in Ghana. ${ }^{7}$ The premium mandate excludes children under... 18 yrs if...parents are registered, pregnant women, above 70 years and the core [extreme] poor ${ }^{8(\mathrm{p} .158)}$ as well as retirees and/or contributors to Social Security and National Insurance Trust. ${ }^{9(p .7)}$ In addition to fees, it is funded by a $2.5 \%$ value added tax and services covered include outpa- 
tient consultations, essential drugs, inpatient care and shared accommodation, maternity care (normal and caesarean delivery), eye care, dental care and emergency

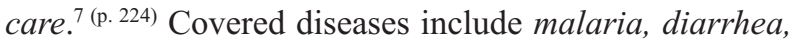
upper respiratory tract infections, skin diseases, hypertension, asthma, diabetes. ${ }^{9}$ Exclusions include most cancers (except breast and cervical) and organ transplants, ${ }^{10,11}$ as well as some medications.

NHIS was implemented just over a decade ago, and various researches have examined facets of its implementation and enrollment. Implementation of NHIS has been found by researchers to have negative and positive outcomes so far. The positive outcomes reported included increased positive birth outcomes ${ }^{9}$ and improved care access for urban women. ${ }^{10}$ Negative outcomes reported included increased responsibilities for healthcare workers. ${ }^{12}$ Attitudes of Ghanaian citizens about NHIS and their enrollment in NHIS were influenced by: gender, wealth, ethnicity, education and religion. ${ }^{13,14}$

Reported enrollment has varied depending on the source with a 2012 NGO showing NHIS: only covered around $18 \%$ of the population when...government...cited coverage as being as high as 67\%...government revised [their later] figures downwards, to around $34 \% .{ }^{15}$ (p. 59)

The private and public sectors agree that actual enrollment needs improvement to reach the stated goal of covering all. The poorest who lack access to healthcare have particular enrollment issues.

Provider-related concerns also remain a challenge to NHIS. NHIS noted recently: Ghana Chamber of Pharmacy nearly cut supply of medicines to health facilities that depend on the NHIS to pay for their medicines. ${ }^{16(\text { (p. } 1)}$ Public hospital doctors went on strike in summer of 2015 to protest lack of payments, working conditions, and medicine shortages. ${ }^{17,18}$

The Ghanaian elderly population is growing and most live in rural areas with limited services. ${ }^{19} \mathrm{Mba}^{20}$ noted the numbers of elderly returning to rural hometowns after urban living, for opportunities in farming. Many call NHIS a role model for other sub-Saharan [African] countries, ${ }^{5\left(\mathrm{p} .{ }^{39)}\right.}$ therefore research on how it impacts the elderly is important.

\section{Materials and Methods}

This study was conducted during June 2012 in Agate (local population estimated at 2500), a rural community about 157 kilometers from the capital, Accra. ${ }^{21}$ Agate (Hohoe Municipality) is in the Volta Region ${ }^{22}$ where most residents work in agriculture. ${ }^{23}$ The 2010 Ghana census estimates the municipality population as approximately $167,016 .{ }^{24}$ (p. 16) Rural residents over 65 years number around $8.6 \%{ }^{24(\mathrm{p} .16)}$ Thirty-eight percent of rural residents utilize water from rivers/streams for drinking ${ }^{24(\text { p. } 57)}$ and $47 \%$ have no toilet in-house. ${ }^{24}$ (p. 59)

Agate's population offered the under-researched and specific demographics targeted: rural, elder poor with various recent illnesses and two research team members had previous experience in Agate. Many households are extended families including elders. Elders often supplement agricultural work with remittances from relatives in cities or abroad. Commonly accessed hospitals are 40-64 kilometers away.

The traditional chief, clan elders, queen mother, family elders, indigenous religious leaders and ritual/religious experts work with the state administrative machinery to address daily activities, needs and community disputes.

Agate is predominantly Christian. Catholic, Evangelical Presbyterian, Anglican, Pentecostal and African Independent churches are represented. Islam has a much stronger presence in northern Ghana and is less common in many of Volta region's rural villages, therefore it was not part of this study. Agate is regionally well-known for its heavy concentration of diverse religious institutions many of which specialize in spiritual healing.

We met with the council of elders and then the village Chief to provide project information and request permission to interview. Our key informant, the chief's son (present during half of total interviews), provided introductions and volunteer access for snowball sampling. Participants' criteria included: experiencing illness within the previous two years and over 50 years old. We performed 28 semi-structured interviews with men and women over a week in June 2012 at participants' dwellings to prevent mobility from being a selection issue and included participants from a diverse (but not representative) selection of the 19+ houses of worship and others who did not attend traditional church. Informed consent was obtained verbally in Ewe dialect and Ewe interviews were performed by one male and one female research team members who were born in Ghana (terminal degrees and research experience in qualitative research, CITIS certification, and Institutional Review Board approval). No participants dropped out, although one was excluded for age. All participants were given a t-shirt or soap as a thank you. Interviews (20 minutes to hour-long in length) were recorded. A chart was completed immediately after interviews among the research team members (on day of interview) to chart immediate interpretation of question responses (for later data cross checking). Interviews were transcribed and translated in the United States by an external paid Ghanaian translator. Transcripts were not reviewed by participants due to budget, and travel limitations, however, for accuracy all transcriptions were rereviewed by an Ewe-speaking interviewers on our team. Photographs we took of participants were delivered a year later to be distributed to participants.

Our goals were the following: to obtain snapshot views of the lives, in relation to health and NHIS, of rural elders in our sample; to explore the sources and level of local knowledge about NHIS; to collect information on why participants had or did not have NHIS; to determine 
differences, similarities, and/or patterns that could be identified in regard to healthcare attitudes, access, and use across and between the groups (NHIS and non-NHIS participants); to examine how those who had NHIS viewed their health experiences and outcomes compared with those who did not have NHIS; to find out what could improve health lives of participants in regard to NHIS.

Matrices were created to record and examine answers to close-ended questions and responses to openended questions were coded (such as positives and negatives of insurance) based on pre-field concepts. Semi-quantification/limited quantification (simple percentages and categorization of most common or 9 out of 28) of close-ended research questions were used to analyze data on our exploratory questions. We subsequently utilized selected (but not all) aspects of constructivist grounded theory ${ }^{25}$ (i.e. literature review performed postanalysis, coding for actions/processes, examination of emergent themes, memoing). To reflect participants' actions, we relied heavily on quotes (in context of interviews) the way people talked about health insurance, and their processes of seeking health care. This revealed other data-derived themes related to NHIS and elder health and well-being that we did not consider in the general study design questions. Data were coded manually, with initial and then focused coding as well as in vivo codes. Repeating themes from interviews were determined by context, phrases, and word usage and these were ordered by mention/importance then subdivided into focused categories (like medical transportation issues and social limiting factors in healthcare). There were two data coders (one primary, one secondary) and the analysis in article was reviewed by both of the onsite interviewers and cross-checked with the day of interview data classification chart.

\section{Results}

Of 28 interviewees, 11 were males and 17 were females. Participation in the study was voluntary and no one refused participation after hearing consent form and questions.

Interviewees were an average of 70.4 years of age (several people did not know their exact age so we always accepted their low estimate, meaning that the average age of our sample was likely older). Sixty-four percent (18 participants; 6 males, 12 females) had current NHIS coverage and 36\% (10 participants; 5 male, 5 female) were not signed up ( 1 had been signed up previously but did not re-enroll).

\section{Participants with and without National Healthcare Insurance Scheme: knowledge}

First, we quantified knowledge (see categories below of solid knowledge, general knowledge, and low/no knowledge) about NHIS in both groups (those with and without NHIS). Overall NHIS knowledge was reported as strong with 15 of all respondents reporting or displaying solid knowledge (sharing detailed insurance working information with us in interview conversation such as specific costs, what was covered/not covered, how it worked). Ten displayed more general knowledge (such as who was eligible or that it was available but not details about cost/coverage) about the insurance, and 3 (all of whom lacked NHIS) possessed no knowledge (knew only of NHIS existence). One of the three lacking knowledge noted, I don't know anything about it. All I know is that it's expensive. Knowledge among the informed came from multiple sources including (in order of mention): gonggong beater (town crier who gives news), government agents, radio, and younger family members who made some health decisions for participants.

We also examined insured and uninsured for knowledge about their medical issues. Participants without NHIS (9 out of 10) appeared to have no named medical diagnosis for most/all of their major complaints while 7 of 18 with NHIS mentioned a named medical condition.

\section{Participants with National Healthcare Insurance Scheme: attitudes}

Next, we examined the perceptions of those with NHIS about health insurance: why they subscribed and ensuing positives and negatives. The perceptions of those with NHIS were strongly positive overall (describing insurance as very good or good). The primary reason for having NHIS was monetary - when people went to doctors/hospitals they reported that it saved them a lot of money. The second strongest positive was the interrelated idea that NHIS saved worrying about money (before illness). Several interviewees reported what treatment access would cost without insurance in highly specific terms: to be hospitalized a bed may cost 200,000 a day $(20 \mathrm{Ghc})$. Imagine being hospitalized for 5 days even before...the medicines. With insurance all of that is waived. For me insurance is good indeed.

Negative concerns about NHIS (from those who had it) were categorized in descending order: cost (lack of coverage of some medications - most common complaint by far, followed by premium costs), ineffectiveness of treatment, lack of knowledge about condition/lack of doctor communication, lack of coverage of transport to doctor, facilities doctors too busy to do tests, and lack of insurance use (perceived as wasted).

While insured participants were more likely to have been to a doctor or hospital recently, several with insurance reported not returning for follow-ups or discontinuing necessary medicines due to lack of coverage by NHIS. One explained: I have health insurance...but ... after the doctor had given me prescription... insurance doesn't cover those drugs. I went another time and they told me the same thing...So I had to pay for the drugs...That's the very rea- 
son I am not able to go (back to doctor) these days.

One participant, diagnosed with glaucoma but unable to afford follow-up medication after treatment, stopped seeing the doctors, explaining, Oh health insurance, it's good in principle except that for me it's not working... you're told it doesn't cover some medicines...insurance only to keep it at home, is that insurance?

Another interviewee accounted for their experience with health insurance in terms of frustration at feeling tricked and taken advantage of: You've been seen by the doctor and gone through all the processes, you are finally told at the dispensary that insurance does not cover the medicines? I thought that was a bit deceptive and unfair. The idea of unfair taking of resources (money) was also expressed by another insured as: I'm telling you the truth. You had to pay that money before you are allowed to go... [hospitals] take money from me before they'll attend to me; so I need to get some money and take along.

People with NHIS discussed ineffectiveness/dissatisfaction of treatment received and lack of information about health conditions, but often did not connect these issues directly to NHIS and their overall satisfaction with it. One interviewee described how: The doctor didn't tell me anything, but he gave me medication. Another explained, I realized that my water (therapy) was working more effectively than the doctor's medicine. One woman described having a hernia and a doctor who assured her it would be removed. When she returned to the hospital the doctor was no longer there and her hernia had never been operated on. Others reported clinics or doctors were too busy to perform x-rays or scans.

\section{Participants without National Healthcare Insurance Scheme: attitudes}

Next we examined the uninsured and their reasons for not having insurance as well as overall attitudes on health/healthcare in their lives. This group was younger than the overall project participant average at 65.5 years compared to 70.4 years, unsurprising since two younger participants mentioned declining coverage due to being healthy. Reasons cited for not enrolling included (in descending order with some participants mentioning more than one reason): six participants discussed religion/spiritual beliefs (only God heals or illness as caused by sin), five mentioned the high cost, two cited doctor mistrust, two noted a lack of 'necessity,' and one implied health choices were made by others in household. At least 3 of the five interviewees who cited high cost as a concern appeared (based on self-description) to qualify for the free NHIS exemption for those 70 years + .

Three participants without NHIS were from a single Christian religious sect (not named here for the sect's privacy reasons) with two of the three citing religious reasons for not subscribing (one citing cost). Two other participants without NHIS were the only project partici- pants to mention traditional beliefs in evil spirits (jujus) in relation to illness.

Several uninsured stated they were thinking about [getting] it or going to get it with one explaining: Oh! [The insurance is] good, it's very good; it's not bad at all.

That's why those of us who feel we're not sick so we won't go for it, we're thinking about it.

The uninsured seemed more likely to have what we called social limiting factors - they were more likely to describe challenges affecting healthcare assistance including: living alone/small households, unmarried/widowed, divorced, taking care of adult children, less help from others, inability to attend church or see doctors (physical and/or transport issues), and/or being part of a spiritual community where home visits (to sick people by pastors/congregants) are not practiced.

\section{Participants with and without National Healthcare Insurance Scheme: outcomes}

Finally, we examined both groups and their self-described health outcomes to see how participants actually fared. The complaints in both groups often overlapped ranging from: strokes to hernia, malaria, eye problems, waist pain, leg ulcers, dizziness, high blood pressure, diarrhea, back pain, knee pain, headaches, earaches, and hernias, among other illnesses and chronic pain. Serious, moderate and minor illnesses were reported fairly evenly in both groups. All previously listed illnesses were reported in both groups. Of the 18 interviewees with insurance, 5 described themselves as being better and satisfied or very satisfied with health outcomes in the past two years. 2 reported themselves as okay (some minor improvement), however, they noted having continuing health issues relating to initial complaints. 11 of 18 with insurance reported clear dissatisfaction with health outcomes (requiring care/having chronic pain). Of the 10 uninsured interviewees, one interviewee described himself as being in perfect health and very satisfied with health outcomes (he initially reported minor illness). One interviewee selfreported as okay (defined as minor improvement) however $\mathrm{s} /$ he noted having re-occurrences relating to initial complaints. The remaining 8 of the 10 without insurance reported clear dissatisfaction with outcomes and continuing health issues. The uninsured were also less likely to have visited a doctor recently for an illness, as described by this interviewee: My recent illness, they say it is stroke. The sickness is if I want to get up, I can't get up. One side of my body won't move. But to tell you the truth, God is my witness, I never went to the hospital.

When questioned on why she was uninsured and did not go to a doctor, she responded, I don 't have money. And they say that the card expires too quickly, but as for Jesus, he never dies, so I pray. The quotes demonstrate not just the inaccessibility of healthcare but how this lack of choice or control due to lack of resources is channeled to the nearest available power: spirituality. 


\section{Discussion}

Self-reported NHIS enrollment was relatively high $(64 \%)$ in our study. This is interesting as Agate is a rural, poor village. It could be a result of our snowball sample limited to participants with recent illnesses (a selective snapshot view rather than non-biased representation of a simple random sample). Nonetheless, we believe the depth of our qualitative interviews done by two Ewe speakers, with whom participants were able to converse freely, does inform the conversation on important issues in regard to NHIS.

\section{National Healthcare Insurance Scheme and enrollment issues}

Our overall goal was to find out what could improve the health lives of our participants in relation to NHIS. Several interviewees without insurance noted that in spite of having chosen against NHIS in the past, they are actively thinking about [enrolling]. There is strong enrollment potential, particularly in the over-70 category where fees are waived. Since most also expressed cost of enrollment as a negative factor, incentives for sign-ups at earlier ages could be explored. Incentives might entice non-registrants who worried that they won't use insurance so early.

Aggressive NHIS campaigns have worked for many with insurance. However, in such a spiritually driven culture, no interviewees received NHIS information from their church. Given the many places of worship and amount of time elders spend there, this is an untapped avenue to increase NHIS enrollment and knowledge.

Addressing social limiting factors and the relative solitude of some elders may increase health care and enrollment in NHIS. Local enrollment events tailored to those without transport or connection, might be used to foster and improve connections to community and health at the same time with wellness events, opportunities for preventative care and screenings, etc. ... where people could also concurrently find out about NHIS.

\section{Coverage/benefit issues and National Healthcare Insurance Scheme}

Continuing enrollment is a challenge that can likely be addressed through improving satisfaction. Our analysis showed that drug coverage was the primary complaint from subscribers, fueling the strongest negative reaction in discourse. We found that lack of medication coverage interfered with some treatment success as several described being unable to finish a course of medications or not returning to visit a doctor since they couldn't afford the medications. Covering all medicines is programmatically expensive, however, not covering certain medicines could be argued as even more expensive. If insured people stop medication prematurely or delay doctor visits (as multiple participants described), more expensive treat- ment may result at a great cost to the program as well as at great social cost.

Lack of transport to hospitals/doctors was a secondary complaint contributing to dissatisfaction among participants. Transportation difficulties appeared to delay doctor visits and encouraged participants to try local remedies first. This could add higher eventual costs to NHIS than providing transportation coverage would. Alternately, increased availability of rural mobile clinics could address access and increase preventative care as well as advertise NHIS.

The research team's support of better transport and mobile clinics should not be perceived as a refutation of existing local health options. Fasting, praying, herbs, laying of hands, and worship were viewed as solace by most of our interviewees (particularly chronic sufferers and those who felt they could not afford insurance) - and as an antidote to illness by some who reported physical results from alternative practices.

\section{Religion, spirituality, and National Healthcare Insurance Scheme}

We found half of uninsured participants (5 of 10) described religious/spiritual considerations influencing their lack of insurance. Like Akazili et al. ${ }^{26}$ we found traditional African religious practitioners without insurance who saw illnesses as spiritually derived and saw little need for western medical practices. Other non-insured participants from a Christian sect saw God as healer and believed that illness was influenced or caused by sin. Some reported their religion allowed or advocated only prayer... for treatment. How strong existing spiritual beliefs and NHIS might better co-exist deserves further address by healthcare outreach specialists. For example, spiritual leaders could function as agents in increasing knowledge about and acceptance of health insurance, of preventative care and of health maintenance. Several religious leaders explained how the role of doctors could be complementary with prayers, fasting and other faith-based healing methods. Leaders concerned about their congregants' health may be tapped as NHIS partners.

\section{Conclusions}

Participants with insurance were generally glad they had it, visited doctors more than the unenrolled, knew more about their conditions than the unenrolled, and had more peace of mind about potential medical expenses. The enrolled reported health outcomes better than those without (although 61\% still had poor outcomes). When all elders were questioned, with and without insurance (even when we included those with some re-occurrences in the positive outcome group), $68 \%$ still reported generally negative outcomes including chronic pain. While enrollment benefits rural elders, challenges remain. For our 
participants, increased medication coverage and transportation and/or mobile clinics would be expected to increase access to and/or completion of treatments. NHIS partnerships with religious/spiritual leaders could also have positive impacts on elder health. While cost is a concern with increased services, healthier citizens could save NHIS money. Returning to the overarching goal of our research, we believe that the health lives of our participants, and others, could be improved not just by expanding tangible services, but by integrating willing spiritual leaders into the insurance enrollment, insurance and health education, illness prevention, and general health support process. Agate, center of healing, is a particularly important venue that could demonstrate, from mobile healthcare to faith-based partnerships, how creative healthcare solutions for rural elders might benefit the system as a whole.

\section{References}

1. World Health Organization. Ghana: looking after its older people. Features 2013. Available from: http://www.who.int/ features/2013/ghana-living-longer/en/

2. Ghana Embassy. Population. 2013. Available from: http://www.ghanaembassy.org/index.php?page=population

3. Ghana Statistical Services. Poverty profile presentation (GLSS6). Accra, Ghana: Ghana Statistical Service; 2014.

4. Mills A, Ataguba J, Akazili J, Borghi J, et al. Equity in financing and use of health care in Ghana, South Africa, and Tanzania: implications for paths to universal coverage. Lancet 2012;380:126-33.

5. Sarpong N, Loag W, Fobil J, et al. National health insurance coverage and socio-economic status in a rural district of Ghana. Trop Med Int Health 2009;15:191-7.

6. Government of Ghana. Ghana at a glance: Available from: http://www.ghana.gov.gh/index.php/about-ghana/ghana-ata-glance

7. Jehu-Appiah C, Aryeetey, G, Agyepong, I, et al. Household perceptions and their implications for enrollment in the National Health Insurance Scheme in Ghana. Health Policy Plann 2012;27:222-33.

8. Jehu-Appiah C, Aryeetey G, Spaan E, et al. Equity aspects of the National Health Insurance Scheme in Ghana: who is enrolling, who is not and why? Soc Sci Med 2011;72:157-65.

9. Mensah J, Oppong J, Schmidt C. Ghana's National Health Insurance Scheme in the context of the health MDGs. An empirical evaluation using propensity score matching. Health Econ 2010;19:95-106.

10. Blanchet NJ, Fink G, Osei-Akoto I. The effect of Ghana's National Health Insurance Scheme on health care utilisation. Ghana Med J 2012;46:76-84.
11. Yerramilli P, Atagubah J. Financing cancer care and control in Ghana. 2014. Available from: http://hgei.harvard.edu/fs/ docs/icb.topic910623.files/DCP3\%20Input\%20-Ghana.pdf

12. Witter S, Arhinful D, Kusi A, Zakariah-Akoto S. The experience of Ghana in implementing a user fee exemption policy to provide free delivery care. Reprod Health Matters 2007; 15:61-71.

13. Dixon J, Luginaah I, Mkandawire P. The national health insurance scheme in Ghana's upper west region: a gendered perspective of insurance acquisition in a resource-poor setting. Soc Sci Med 2014;122:103-12.

14. Dixon J, Tenkorang EY, Luginnah I. Ghana's national health insurance scheme: a national level investigation of members' perceptions of service provision. Int Health Hum Rights 2013;13:35.

15. Ghana pharmaceuticals and healthcare report Q3 2015. London: Business Monitor International; 2015.

16. National Health Insurance Scheme. NHIS providers suspend decision to charge cardholders. 2015. Available from: http://www.nhis.gov.gh/News/nhis-service-providers-suspend-decision-to-charge-cardholders-4052

17. Ghana Web. Doctors strike: 500 dead in 17 days. 2015. Available from: http:/www.ghanaweb.com/GhanaHomePage/NewsArchive/Doctors-strike-500-dead-in-17-days375648

18. Laary D. Patients abandon government hospitals as doctors' strike deepens. Africa News. 2015. Available from: http:// www.theafricareport.com/West-Africa/ghana-patients-abandon-govt-hospitals-as-doctors-strike-deepens.html

19. Mba CJ. Population ageing and poverty in rural Ghana. Available from: http://wikieducator.org/images/2/26/AGRIC chuksmba.pdf

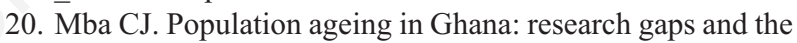
way forward. J Aging Res 2010;2010:672157.

21. Ghana Districts. Available from: http://www.ghanadistricts. $\mathrm{com} /$

22. Government of Ghana. Volta Region. Available from: http: //www.ghana.gov.gh/index.php/about-ghana/regions/volta

23. Ghana Statistical Service. Summary report of final results. Accra, Sakoa Press: 2012. Available from: http://www.statsghana.gov.gh/docfiles/2010phc/Census2010_Summary_ report_of final_results.pdf

24. Ghana Statistical Service. Population and housing census Hohoe municipality. District analytical report. Accra, Sakoa Press: 2010. Available from: http://www.statsghana. gov.gh/docfiles/2010_District_Report/Volta/Hohoe\%20M un.pdf

25. Charmaz K. Constructing grounded theory: a practical guide through qualitative analysis. London: Sage; 2006.

26. Akazili J, Welaga P, Bawah A. Is Ghana's pro-poor health insurance scheme really for the poor? Evidence from Northern Ghana. BMC Health Services Res B 2014;14:637. 